\title{
Comparison of Plug-In Hybrid Electric Vehicle Battery Life Across Geographies and Drive Cycles
}

\author{
Kandler Smith, Matthew Earleywine, Eric Wood, Jeremy Neubauer and Ahmad Pesaran \\ National Renewable Energy Laboratory
}

\begin{abstract}
In a laboratory environment, it is cost prohibitive to run automotive battery aging experiments across a wide range of possible ambient environment, drive cycle, and charging scenarios. Because worst-case scenarios drive the conservative sizing of electric-drive vehicle batteries, it is useful to understand how and why those scenarios arise and what design or control actions might be taken to mitigate them. In an effort to explore this problem, this paper applies a semi-empirical life model of the graphite/nickel-cobaltaluminum lithium-ion chemistry to investigate calendar degradation for various geographic environments and simplified cycling scenarios. The life model is then applied to analyze complex cycling conditions using battery charge/ discharge profiles generated from simulations of plug-in electric hybrid vehicles (PHEV10 and PHEV40) vehicles across 782 single-day driving cycles taken from a Texas travel survey. Drive cycle statistics impacting battery life are compared to standard test cycles.
\end{abstract}

\section{INTRODUCTION}

Electric-drive vehicles (EDVs) offer the potential to reduce reliance on fossil fuels; however, the fuel displacement of EDVs will be elusive until they achieve meaningful market penetration. Batteries are often the most expensive component of the EDV. Further reductions in battery cost, weight, and volume are required to make the vehicles more attractive in the marketplace. To compete with conventional vehicles, EDVs and their batteries must achieve a 10- to 15year life [1]. Cost analyses of light-duty EDVs generally show that periodic battery replacement (e.g., every 5 years) is not warranted and the battery should be designed to last the life of the vehicle [2]].
A battery's aging behavior directly impacts the applications and environments to which it is suited and to what degree the battery must be oversized to achieve the desired service life. Unlike batteries for consumer electronics, automotive batteries face large variations in thermal environment and duty-cycle. Hybrid-electric vehicle (HEV) batteries presently achieve more than 10 years of life by using a small portion, generally less than $25 \%$, of their total energy. Conservatism in battery sizing directly impacts battery cost. Worst-case aging conditions drive the need to oversize batteries, and it is important to explore degradation impacts for a range of possible duty cycles to identify and understand such worst cases. Control strategies that extend battery life may also help reduce the market cost of EDVs.

From the system perspective, significant stressors to a lithium-ion (Li-ion) battery include exposure to high temperatures, exposure to high states of charge (SOCs) and charge voltages, calendar age, depth of discharge (DOD), and the rate and frequency of charge/discharge cycles. Various models in the literature, ranging from physics-based $[\underline{3}, \underline{4}]$ to semi-empirical $[\underline{5}, \underline{6}]$ and empirical $[\underline{7}, \underline{8}, \underline{9}]$, describe the dependence of battery resistance and capacity fade on various aging factors. Based on aging datasets for the graphite/nickelcobalt-aluminum (NCA) Li-ion chemistry, the authors $[\underline{6}, \underline{10}]$ developed a physically justified semi-empirical model allowing interpolation/extrapolation from laboratory-tested conditions to arbitrary duty cycles likely to be encountered in real-world environments. The life degradation model is suitable for battery system engineering and techno-economic analysis of Li-ion batteries.

This paper specifically considers aging scenarios for plug-in hybrid electric vehicles (PHEVs) with 10 and 40 mile (16 and $64 \mathrm{~km}$, respectively) nominal electric ranges. The PHEVs, referred to as PHEV10 and PHEV40, respectively, have two modes of operation. In the charge depletion (CD) mode, 
vehicle motive power is primarily provided by the battery. When the CD energy is depleted, the vehicle switches to a charge sustaining (CS) mode supported by both a gasolinefueled internal combustion engine and battery-powered motor. Recharge of the battery is achieved by connection to the electrical grid.

The paper is organized as follows. Section II summarizes the battery life model and gives example results for the graphite/NCA chemistry. Section III analyzes battery aging with time under variable temperature and SOC conditions representative of a PHEV10 and PHEV40 in 100 different geographic areas throughout the United States. Section IV analyzes battery aging for a distribution of hypothetical PHEV cycling scenarios. The cycling scenarios are generated by simulating PHEV10 and PHEV40 vehicles using 782 second-by-second speed-versus-time driving profiles recorded during single-day travel surveys of light-duty vehicles in Texas.

\section{LIFE MODEL}

\section{MODEL DESCRIPTION}

Battery aging is caused by multiple phenomena related to both cycling and time. Battery degradation is accelerated with the DOD and frequency of cycling, elevated temperature, and elevated voltage exposure, among other factors. At the battery terminals, the observable effects of degradation are an increase in resistance and a reduction in capacity. These two effects can be correlated with power and energy losses that cause battery end-of-life in an application. Mechanisms for resistance growth include loss of electrical conduction paths in the electrodes, fracture and isolation of electrode sites, growth of film layers at the electrode surface, and degradation of electrolyte. Mechanisms for capacity loss include fracture, isolation, and chemical degradation of electrode material, as well as permanent loss of cyclable lithium from the system as a byproduct of side reactions.

Under storage conditions, the dominant fade mechanism is typically growth of a resistive film layer at the electrode surface. As the layer grows, cyclable lithium is also consumed from the system, reducing available capacity. In the present model, resistance growth and lithium capacity loss are assumed to be proportional to the square-root of time, $t^{1 / 2}$, typical of diffusion-limited film-growth processes [3]. Under cycling-intense conditions, degradation is mainly caused by structural degradation of the electrode matrix and active sites. Cycling-driven degradation is assumed to be proportional to the number of cycles, $N$.

Cell resistance growth due to calendar- and cycling-driven mechanisms is assumed to be additive:

$$
R=a_{0}+a_{1} t^{1 / 2}+a_{2} N
$$

Cell capacity is assumed to be controlled by either loss of cyclable Li or loss of active sites:

$$
Q=\min \left(Q_{L i}, Q_{\text {sites }}\right)
$$

where

$$
\begin{gathered}
Q_{L i}=b_{0}+b_{1} t^{1 / 2} \\
Q_{\text {sites }}=c_{0}+c_{1} N
\end{gathered}
$$

Equations $(2, \underline{3}, \underline{4)}$ are simplifications of observations from experimental data [11]. Note that electrode site capacity, $Q_{\text {sites }}$, in (2) may be expanded to include separate terms for negative electrode sites and positive sites; however, it is typical for one electrode to limit active-site capacity and hence only one site-capacity term is included here.

Models (1), (3), and (4) are readily fit to a resistance or capacity trajectory measured for one storage or cycling condition. With multiple storage- and cycling-condition datasets, functional dependence can be built for rate constants $a_{1}\left(T, V_{o c}, \triangle D O D\right), a_{2}\left(T, V_{o c}, \Delta D O D\right), \quad b_{1}\left(T, V_{o c}, \triangle D O D\right)$, and $c_{1}\left(T, V_{o c}, \triangle D O D\right)$. For a general rate constant $\theta$, the present model assumes Arrhenius dependence on temperature $T$ :

$$
\theta_{T}=\exp \left[\frac{-E_{a}}{R}\left(\frac{1}{T(t)}-\frac{1}{T_{r e f}}\right)\right]
$$

Tafel dependence on open-circuit voltage $V_{o c}$ :

$$
\theta_{V}=\exp \left[\frac{\alpha F}{R}\left(\frac{V_{o c}(t)}{T(t)}-\frac{V_{r e f}}{T_{r e f}}\right)\right]
$$

and Wöhler dependence [12] on individual swings in depthof-discharge $\triangle D O D$ :

$$
\theta_{\Delta D o D}=\left(\frac{\Delta D O D}{\Delta D O D_{r e f}}\right)^{\beta} .
$$


The combination of individual stress factors is assumed to be multiplicative:

$$
\theta=\theta_{\text {ref }} \Pi \theta_{k}
$$

The life model was fit to laboratory aging datasets $[\underline{13}, \underline{14}$, $\underline{15}, \underline{16}]$ for the Li-ion graphite/NCA chemistry. The NCA chemistry has generally graceful aging characteristics and is expected to achieve 8 or more years of life when sized appropriately for a vehicle application. The present model does not capture possible accelerating fade mechanisms that could occur beyond $30 \%$ capacity fade. Other degradation mechanisms not captured by the model include fast chargerate effects (other than temperature rise), the effect of extreme temperatures $\left(>50^{\circ} \mathrm{C},<0^{\circ} \mathrm{C}\right)$, sudden damage due to exceeding typical operating conditions, cell-to-cell manufacturing variation, infant mortality due to latent manufacturing defects, and long-term degradation effects that may occur beyond 10 years of life.
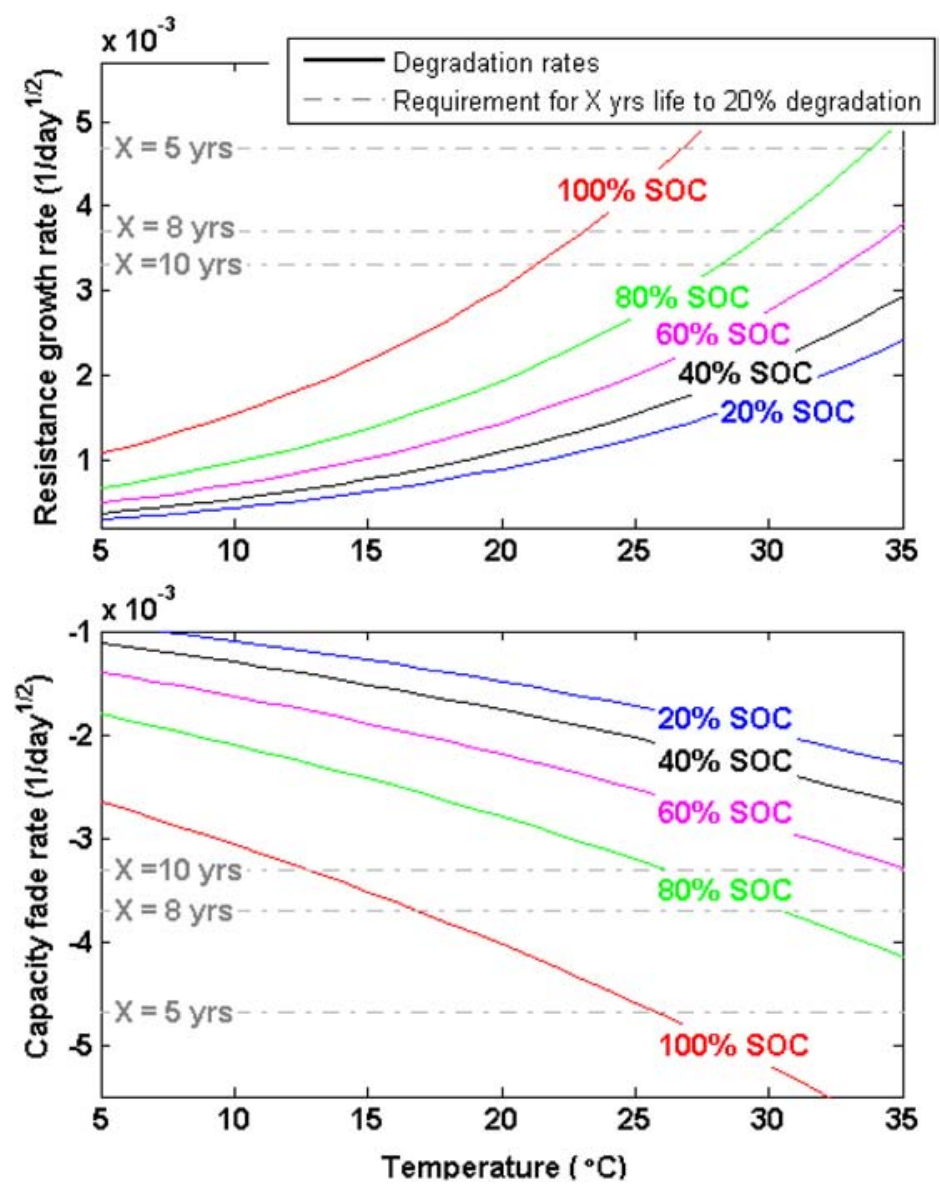

Figure 1. Typical graphite/NCA degradation rates for storage at constant SOC and temperature (solid lines). Dotted lines show maximum allowable degradation rates for example end-of-life requirements of $20 \%$ resistance growth and $20 \%$ capacity fade.
Figure 1 shows resistance and capacity fade rates for storage at different constant temperatures and SOCs. Fade rates are relatively insensitive to temperature when the cell is stored at less than $40 \%$ SOC. At SOC greater than $80 \%$, there is strong sensitivity to temperature. The life model captures SOC/ temperature interaction using the exponential of $V_{o c} / T$ term in Eq. (6). In Figure 1, dotted lines provide reference examples of maximum allowable degradation rates to achieve 5,8 , and 10 years of service life. These examples assume battery endof-life is controlled by $20 \%$ cyclable-lithium capacity loss and $20 \%$ resistance growth (17\% power loss). The value of $20 \%$ degradation is arbitrarily chosen for this example. Note that cycling will cause additional degradation to the storage results shown in Figure 1. Comparison of the 5-, 8-, and 10year life degradation-rate limits make apparent what temperatures and SOC combinations are acceptable to achieve desired service-life requirements under storage conditions.

\section{DUTY-CYCLE METRICS}

For the purpose of comparing degradation resulting from variable temperature and cycling profiles, life model equations (1), (2), (3), (4), (5), (6), (7), (8) suggest useful metrics for comparison of duty cycles on the basis of effective temperature,

$$
T_{e f f}=\frac{\left(-E_{a}+\alpha F V_{o c, a v g}\right) / R}{\ln \left\{\frac{1}{t_{d a y}} \int_{0}^{d a y} \exp \left[\left(-E_{a}+\alpha F V_{o c}(t)\right) / R T(t)\right] d t\right\}}
$$

effective open-circuit voltage,

$$
V_{o c, e f f}=\frac{\ln \left\{\frac{1}{t_{d a y}} \int_{0}^{a x y} \exp \left[\alpha F V_{o c}(t) / R T(t)\right] d t\right\}}{\alpha F / R T_{\text {avg }}}
$$

which can be expressed as effective SOC using look-up tables, $S O C_{e f f}=f\left(V_{o c, e f f}\right)$, and effective cycles-per-day,

$$
\dot{N}_{e f f}=\left[\frac{1}{t_{d a y}} \sum_{i} N_{i}\left(\frac{\Delta D O D_{i}}{\Delta D O D_{r e f}}\right)^{\beta}\right]^{1 / \beta} .
$$

With $\triangle D O D_{r e f}=1$, Eq. (11) is an effective number of $100 \%$ $\triangle D O D$ cycles per day.

\section{BATTERY AGING UNDER STORAGE GEOGRAPHIC AMBIENT CONDITIONS}

The geographic region in which a battery is used directly influences the average lifetime temperature of the battery. To 
estimate possible distributions of future PHEV market penetration throughout the United States, we consider 100 geographic locations with the greatest HEV light-duty vehicle registration in 2010 as determined by the Polk Company [17]. Analyzing those 100 locations using typical meteorological year (TMY) data [18], the hottest three cities based on annual average temperature are Honolulu, Hawaii; Miami Florida; and Phoenix, Arizona; with Honolulu the hottest based on annual average temperature. Note that Phoenix becomes the worst-case hot location when the impact of peak summertime temperature and solar radiation are taken into account. The coldest three cities are Portland Maine; Madison, Wisconsin; and Minneapolis Minnesota; with Portland the coldest based on annual average temperature. The median city is Baltimore, Maryland. Figure 2 shows example temperature data for Phoenix.

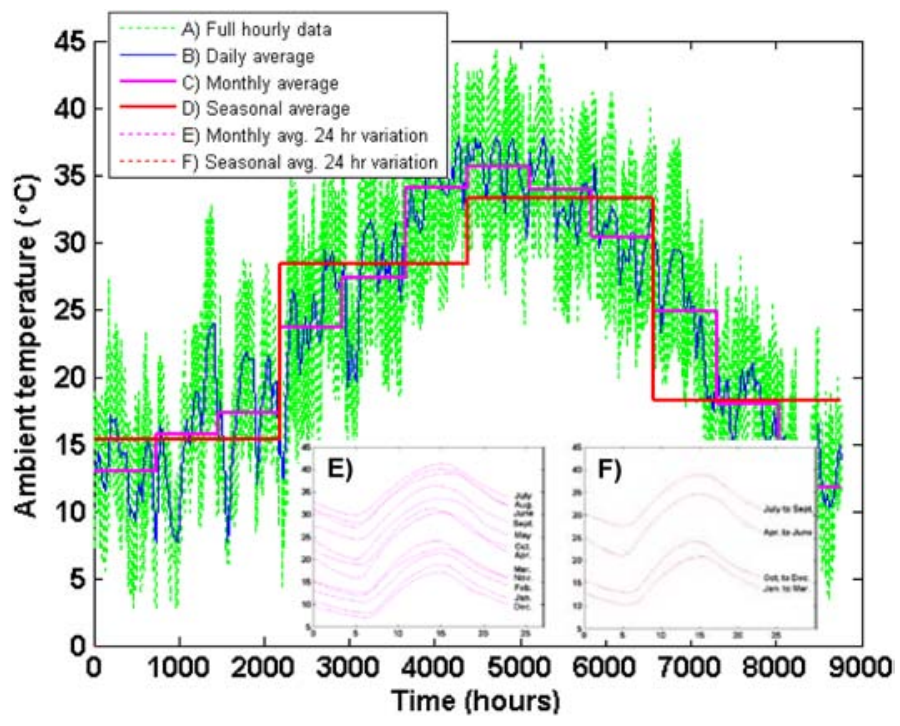

Figure 2. TMY temperature data for Phoenix, Arizona.

\section{VEHICLE PASSIVE THERMAL ENVIRONMENT}

In addition to ambient temperature, battery temperature is also affected by solar radiation when the vehicle is parked in the sun. Figure 3 shows a thermal network model used to simultaneously consider ambient temperature and solar radiation effects on battery temperature. Using Matlab System Identification Toolbox, thermal model parameters (Table 1) were fit to match hourly measurements of ambient, battery, and cabin temperatures and solar radiation for a 2005 Toyota Prius HEV parked during three days of testing in Golden, Colorado. An additional one year of testing in Phoenix on a similar Prius validated the thermal model's prediction of battery temperature to within $1 / 2^{\circ} \mathrm{C}$ for the Phoenix environmental conditions [19].

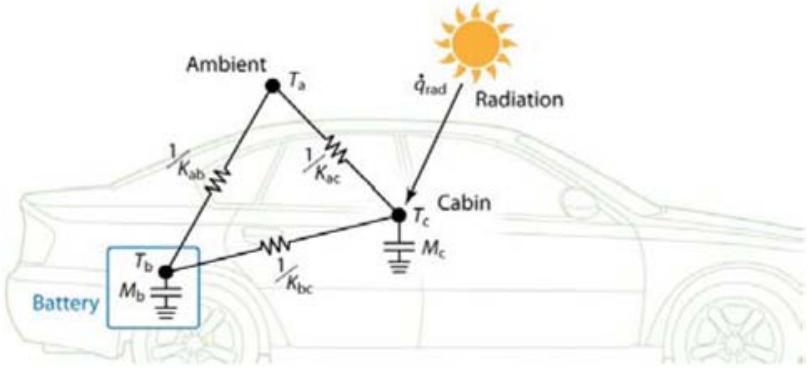

Figure 2. Thermal network model for prediction of battery temperature variation in various environments.

Table 1. Thermal Network Model Parameters for 2005 Toyota Prius.

\begin{tabular}{lccc}
\hline & $\begin{array}{c}\text { HEV } \\
\text { NiMH }^{1}\end{array}$ & $\begin{array}{c}\text { PHEV10 } \\
\text { Li-ion }^{2}\end{array}$ & $\begin{array}{c}\text { PHEV40 } \\
\text { Li-ion }^{2}\end{array}$ \\
\hline \hline$M_{b}(\mathrm{~J} / \mathrm{K})$ & 35,600 & 42,970 & 146,590 \\
\hline$K_{a b}(\mathrm{~W} / \mathrm{K})$ & 0.6498 & 0.4641 & 1.049 \\
\hline$K_{a c}(\mathrm{~W} / \mathrm{K})$ & 1.316 & 1.316 & 1.316 \\
\hline$K_{b c}(\mathrm{~W} / \mathrm{K})$ & 0.4663 & 0.3331 & 0.7527 \\
\hline$M_{c}(\mathrm{~J} / \mathrm{K})$ & 10,177 & 10,177 & 10,177 \\
\hline$\varepsilon A_{c}\left(\mathrm{~m}^{2}\right)$ & 0.068 & 0.068 & 0.068 \\
\hline
\end{tabular}

1Nickel metal hydride battery. Parameters fit to data from 2005 Toyota Prius HEV.

2Parameters used for this study, adjusted to account for larger thermal mass and surface area of PHEV packs.

To analyze PHEV batteries in this study, $M_{b}, K_{a b}$, and $K_{b c}$ re scaled from the Prius HEV to capture the greater thermal mass and surface area of PHEV10 and PHEV40 battery packs (Table 1). The Prius body type may represent something of a worst case for solar radiation impact on battery temperature as its battery is located in close proximity to the passenger cabin and the windshield and hatchback windows have shallow slopes. Solar radiation on a PHEV with a Prius-like body type and battery location that is parked in full sun can increase the yearly average battery temperature by $1.3^{\circ} \mathrm{C}$ to $3.1^{\circ} \mathrm{C}$ relative to a vehicle experiencing no solar radiation. This number varies with the solar intensity of the geographic location and battery thermal mass. The battery thermal mass attenuates the magnitude of daily battery temperature swings compared to daily ambient temperature swings. This attenuation damps out the impact of peak daily temperatures on battery life. Battery fade rates are on the order of $1 \%$ slower when accounting for attenuated daily temperature swings due to battery thermal mass using the vehicle thermal network model compared to assuming battery temperature equal to ambient temperature. 


\section{AGING AT VARIABLE TEMPERATURE AND CONSTANT SOC}

Figure 3 shows capacity fade of a PHEV10 battery under storage conditions in worst-case hot and cold cities, with temperatures simulated using the vehicle thermal network model. Small fluctuations visible in capacity fade rate with time correspond to variable seasonal temperatures throughout each year. Accounting for solar radiation through simulation of the battery in its passive thermal environment has obvious importance for predicting battery life in solar-intense environments. In Figure 3, for Phoenix the difference between the ambient-only and ambient + solar curves is 2.0 years or $21 \%$ difference in years to $80 \%$ remaining capacity (Figure 3 inset). This result also suggests a difference in battery life for vehicles parked in the shade versus in the sun, although the magnitude of the difference may be less for vehicles that are driven regularly.

In the experimental life testing of batteries, it is useful to reduce annual temperature variation to a simplified temperature profile. Four-season tests, using seasonal average temperature (green dashed line in Figure 3), provide a reasonable approximation of the full hour-by-hour temperature profile when predicting life under storage conditions. In contrast, simplification of the full temperature data to a single yearly average temperature (blue dotted line) does not reliably reproduce the battery fade pattern, particularly for climates with large seasonal temperature variation, such as Portland, Maine.

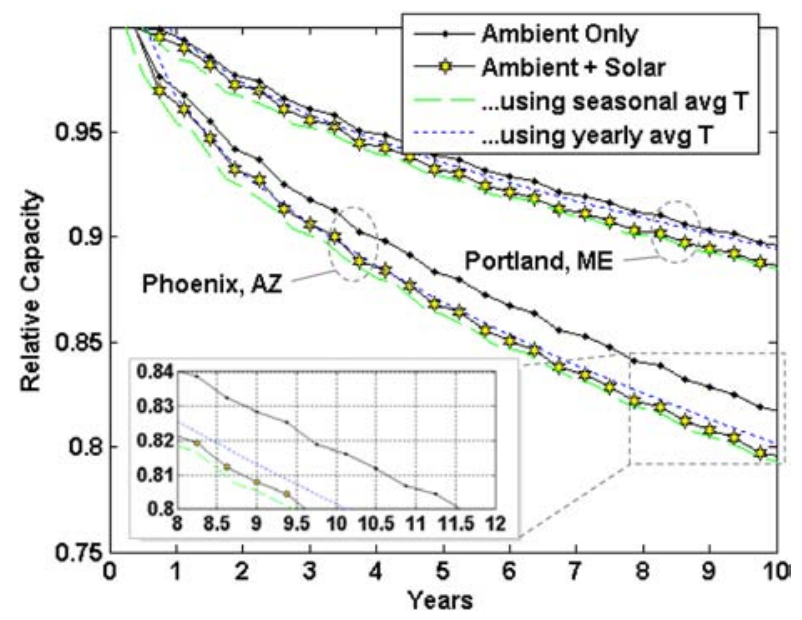

Figure 3. Capacity fade under storage at $90 \%$ SOC for two geographic locations with and without impact of solar loading on the parked vehicle. All cases utilize the vehicle thermal network model (Figure 2). Blue and green curves consider various simplifications of the full hour-by-hour temperature data and should be compared to the ambient + solar case.
Figure 4 is similar to Figure 1, but now considers the impact of variable battery temperature resultant from hourly ambient temperature profiles and solar loading on the vehicle cabin for the PHEV10 and PHEV40 in the 100 climates. Result are given at several constant values of SOC. The dotted lines in Figure 4 provide reference degradation rates for aging at constant temperature (similar to Figure 1). Here, the PHEV batteries (symbols) age at a faster rate compared to what one would conclude if analysis were based on average yearly ambient temperature (dotted lines). This is due to (i) accelerated wear caused by peak summer-seasonal temperatures and (ii) temperature rise due to solar radiation. Not shown, the variable temperature PHEV simulation results for 100 cities would fall directly on top of the constant temperature lines if variable temperature results were plotted using effective battery aging temperature (Eq. 9) on the $\mathrm{x}$ axis rather than average yearly temperature.
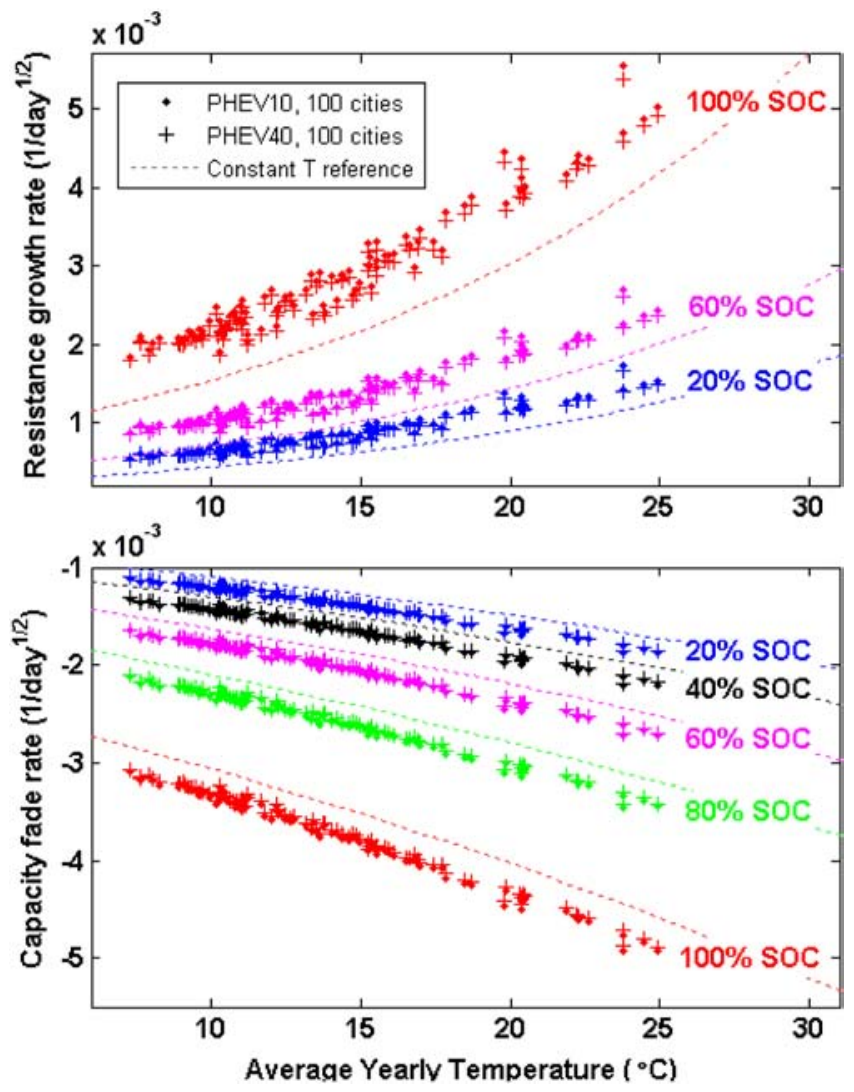

Figure 4. Resistance growth and capacity fade rates under storage at constant SOCs. Reference lines show results for constant temperature. Symbols show simulated results for PHEVs using hour-by-hour TMY ambient temperature and solar radiation data for 100 U.S. cities. 
PHEV10 batteries ("small-filled diamond" symbols) show slightly more degradation than PHEV40 batteries ("plus" symbols) when stored in variable-temperature environments. The smaller PHEV10 batteries have less thermal mass, resulting in wider daily temperature swings and higher peak temperatures each day. Under pure storage conditions, small batteries, including those in HEVs and short-electric-range PHEVs, may benefit from thermal insulation to passively reduce daily peak temperatures. Insulation, however, is only effective for battery designs that employ some means of active cooling during driving and charging. For insulation to be advantageous, the active cooling system must remove at least as much heat as would normally be passively dissipated to ambient as with a non-thermally insulated system.

In addition to thermally isolating the battery from the cabin, battery life will also benefit by avoiding long dwells at high SOC during peak summertime temperatures. The latter can be achieved by oversizing the battery and prohibiting operation at the highest SOCs by enforcing a maximum SOC limit $<100 \%$. Too avoid excessive oversizing, alternative designs might still allow operation of the batteries at high SOCs under moderate conditions, but take extra measures when the vehicle is parked in extremely hot conditions. If a grid connection is available, the cooling system might be allowed to run with some regular duty cycle. Or, lacking a grid connection or suitable cooling system, energy might simply be drawn out of the battery while the vehicle is parked until an acceptable SOC for long-term storage at high temperatures is reached (see Figure 1).

\section{AGING AT VARIABLE TEMPERATURE AND SOC}

Strictly speaking, it is not possible to vary SOC without charge/discharge cycling of the battery. Studies of solidelectrolyte interface (SEI) growth under both storage and cycling conditions generally show that SEI growth predominantly correlates with time, not with number of cycles. SEI growth-rate with time is determined by SOC, temperature, and SEI thickness. In this manner, it is appropriate to consider variable SOC and temperature and their combined impact on time-related aging $\left[t^{1 / 2}\right.$ terms in Eqs. (1) and (3)].

Five variable SOC scenarios are used to investigate temperature and SOC interactions with time. Table 2 and Figure 5 define the five single-day SOC profiles. These simplified profiles all assume two hours of driving per day, one hour to deplete $\mathrm{CD}$ energy to $20 \% \mathrm{SOC}_{\min }$, and two hours to recharge. Two values of $\mathrm{SOC}_{\max }, 80 \%$ and $100 \%$, are considered. Scenarios I and II consider a single driving trip per day. Scenarios III, IV, and V consider two driving trips per day. In scenarios I, II, and IV batteries are recharged immediately after each driving trip and thus have high average SOCs, near $\mathrm{SOC}_{\max }$. Scenario $\mathrm{V}$ employs a just-intime charging strategy in which the start of charging is delayed as late as possible but still meets the constraint of achieving full-charge in time for the next driving trip. This scenario has the lowest average $\mathrm{SOC}$, near $\mathrm{SOC}_{\mathrm{min}}$. Based on the previous results we expect this low-SOC scenario to have the lowest fade rate.

Table 2. Average SOC for five variable SOC scenarios. All use $S O C_{\min }=20 \%$.

\begin{tabular}{llcc}
\hline & & $80 \% \mathrm{SOC}_{\max }$ & $100 \% \mathrm{SOC}_{\max }$ \\
\hline \hline I) & Trip at 2:00 & $74 \%$ & $92 \%$ \\
\hline II) & Trip at 14:00 & $74 \%$ & $92 \%$ \\
\hline III) & $\begin{array}{l}\text { Two trips at 8:00 \& 17:00 } \\
\text { One Baseline Charge }\end{array}$ & $54 \%$ & $65 \%$ \\
\hline IV) & $\begin{array}{l}\text { Two trips at 8:00 \& 17:00 } \\
\text { Two Opportunity Charges }\end{array}$ & $73 \%$ & $90 \%$ \\
\hline V) & $\begin{array}{l}\text { Two trips at 8:00 \& 17:00 } \\
\text { One Just-in-Time Charge }\end{array}$ & $24 \%$ & $25 \%$ \\
\hline
\end{tabular}

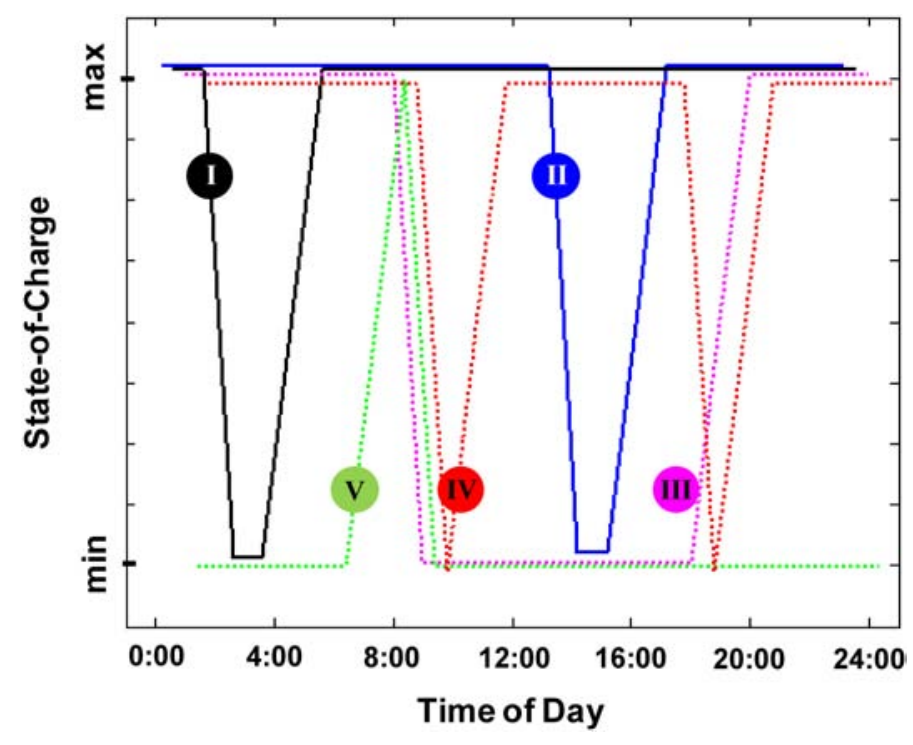

Figure 5. Five variable SOC scenarios. Descriptions are given in Table 2. (SOC profiles include slight offsets for clarity.)

Figure 6 shows degradation rates for the five scenarios and two maximum SOC limits. For the same $\mathrm{SOC}_{\max }$, there is negligible difference in degradation rate between scenarios I and II. The only difference between these two single-drivingtrip-per-day scenarios is the time of day of the trip: In scenario I, the driving trip occurs at 2:00 during the night when daily temperatures are coolest, whereas in scenario II, the trip occurs at 14:00 in the afternoon when daily temperatures are hottest. Time of day of SOC variation does not matter much when the battery temperature fluctuations 
are only determined by the passive thermal environment. Scenario IV, consisting of two driving trips, at 8:00 in the morning and 17:00 in the late afternoon, each followed by an opportunity charge, produces similar aging results to scenarios I and II. This is not surprising as scenarios I, II, and IV all have similar average daily SOC (Table 2).

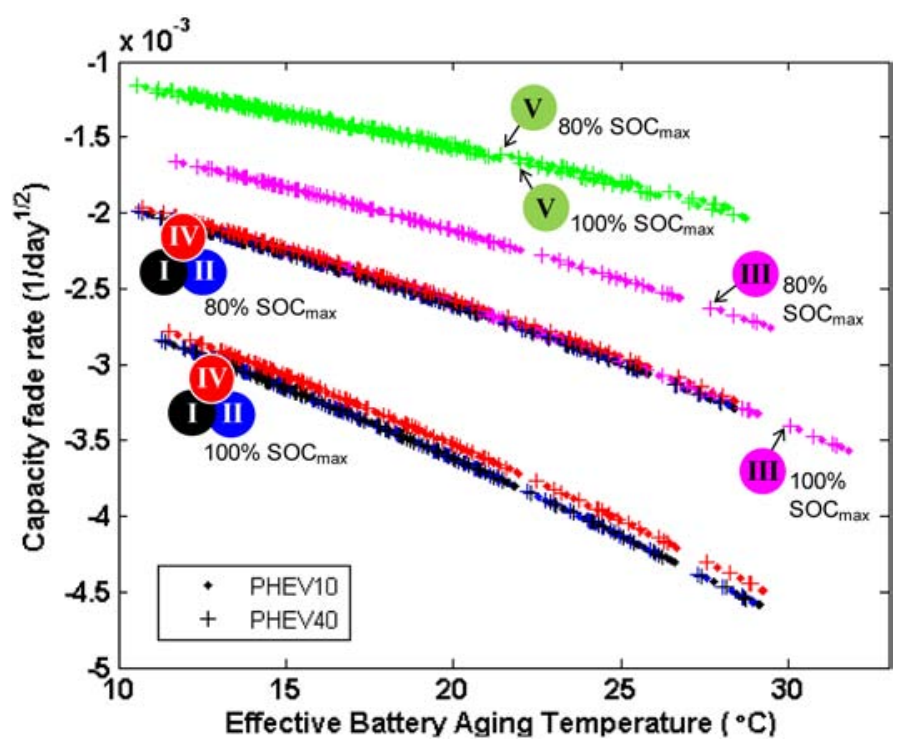

Figure 6. Capacity fade rate for batteries stored in Priuslike thermal environment, 100 geographic locations, and five variable SOC scenarios described in Table 2.

The two maximum SOCs investigated are $\mathrm{SOC}_{\max }=80 \%$ and $100 \%$. Lowering $\mathrm{SOC}_{\max }$ from $100 \%$ to $80 \%$ adds considerable expense to the battery, as a larger battery is needed to meet the vehicle's useable $\mathrm{CD}$ energy requirement. On the other hand, the lower SOC greatly reduces storagerelated fade for hot climates. For scenarios I, II, III, and IV, fade rates are some $25 \%$ to $30 \%$ lower when battery operation is restricted to $80 \% \mathrm{SOC}_{\max }$ versus allowing full utilization up to $100 \% \mathrm{SOC}_{\max }$. The just-in-time charging scenario $\mathrm{V}$, however, shows little sensitivity to $\mathrm{SOC}_{\max }$ as that scenario keeps the average SOC low regardless of $\mathrm{SOC}_{\max }$ limit (Table 2). The result points to a tangible benefit to battery life by delaying the beginning of charge until several hours before the next driving trip. In practice, it will be difficult to realize the full benefits of just-in-time charging without good knowledge of when the next driving trip will occur.

\section{BATTERY AGING UNDER CYCLING}

A challenge in battery life prediction is that aging effects take place across multiple time scales:

1. Desired battery life time $\sim 10$ years

2. Changes in duty-cycle (due to adaptive controls, battery swapping, vehicle resale, etc.) $\sim 1$ month to 5 years
3. Seasonal thermal variation $\sim 3$ months

4. Daily thermal variation $\sim 24$ hours

5. Drive cycle thermal variation $\sim 10$ s of minutes

6. SOC variation $\sim 10$ s of seconds to hours

The previous sections compared the impact of variable temperature and SOC on battery calendar life during storage. This section presents initial work towards comparison of the impact of variable PHEV cycling profiles on battery cycle life. In the initial investigation of drive cycles, daily and seasonal temperature variations are neglected. Changes in duty cycle during the battery life are also not considered.

\section{VEHICLE DRIVE CYCLES}

This analysis considers two midsize PHEV passenger sedans with batteries providing nominal 10- and 40-mile all-electric ranges for the Urban Dynamometer Driving Schedule (UDDS) driving cycle (Table 3). Drive cycles are taken from a Texas Department of Transportation travel survey in San Antonio and Austin, Texas [20]. The survey used GPS loggers to record speed vs. time for 782 individual light-duty vehicles over 24 hours. A NREL study used the 782 drive cycles to estimate fuel economy of PHEV10 and PHEV40 sedans relative to conventional vehicles across variable drive cycles [21].

Table 3. Vehicle model parameters.

\begin{tabular}{llcc}
\hline & & PHEV10 & PHEV40 \\
\hline \hline \multirow{5}{*}{ Vehicle } & All-electric range, km & 16.7 & 67 \\
\cline { 2 - 4 } & Total vehicle mass, kg & 1,714 & 1,830 \\
\cline { 2 - 4 } & Electric motor power, kW & 40 & 43 \\
\cline { 2 - 4 } & IC engine power, kW & 77 & 80 \\
\hline \multirow{5}{*}{ Battery } & Useable power, kW & 44 & 48 \\
\cline { 2 - 4 } & Useable energy, kWh & 2.67 & 11.48 \\
\cline { 2 - 4 } & Maximum SOC & $80 \%$ & $90 \%$ \\
\cline { 2 - 4 } & Minimum SOC at BOL & $30 \%$ & $30 \%$ \\
\cline { 2 - 4 } & Excess energy at BOL & $13 \%$ & $10 \%$ \\
\cline { 2 - 4 } & Excess power at BOL, 10\% SOC & $43 \%$ & $43 \%$ \\
\hline
\end{tabular}

$\mathrm{BOL}=$ beginning of life

$\mathrm{EOL}=$ end of life

$\mathrm{IC}=$ internal combustion

For prediction of battery life, it is necessary to make assumptions on how often each drive cycle occurs. The present analysis considers each drive cycle individually and neglects variability in daily travel. One day of rest is assumed for each 6.8 days of driving. This weighting is chosen so that the average travel distance from the Texas survey, 38.9 

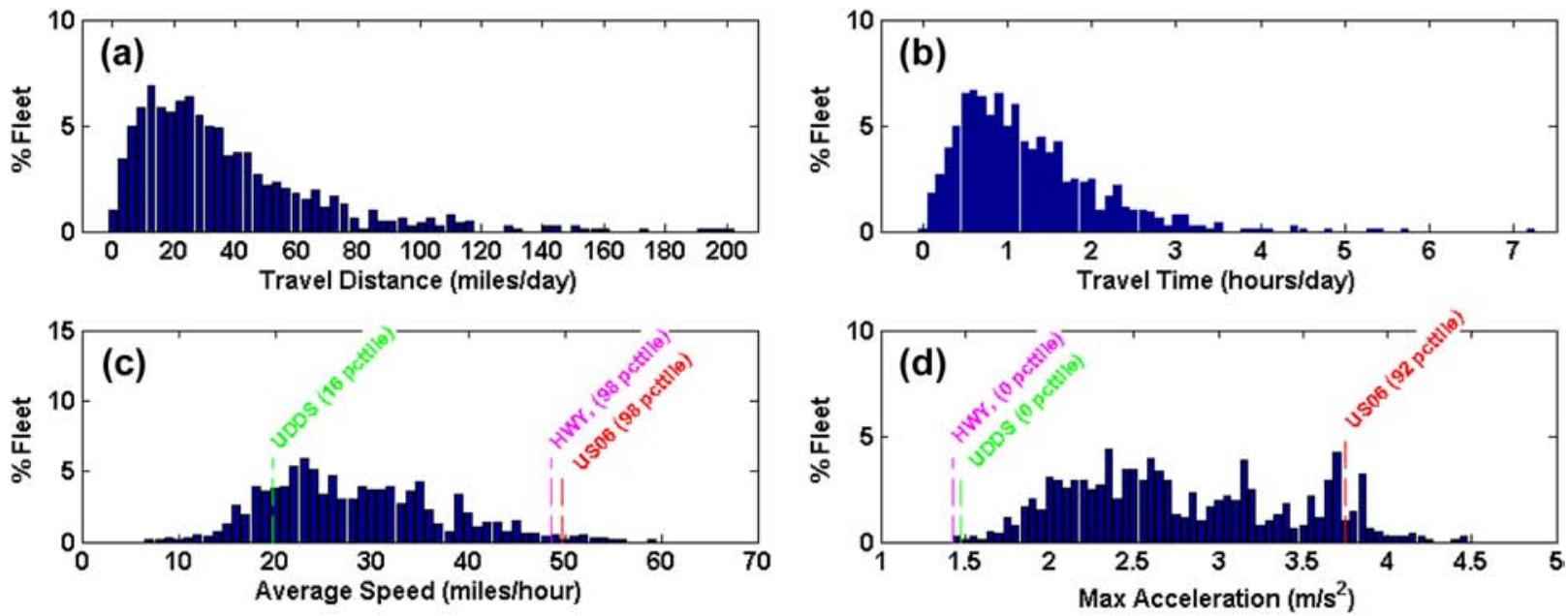

Figure 7. Drive-cycle metrics (a) distance-traveled per day, (b) travel time per day, (c) average speed while driving, and (d) maximum acceleration. Blue histograms represent 782 drive-cycles from Texas survey.

miles/day (62.6 km/day), matches the U.S. national average for annual distance traveled, 12,375 miles/yr $(19,916 \mathrm{~km} / \mathrm{yr})$ [22].

Simulations assume the PHEV batteries are recharged at a 1.6 $\mathrm{kW}$ rate following the final driving trip of the day. Vehicle simulation outputs are battery $I^{2} R$ heat generation during driving and charging, temperature, SOC and open-circuit voltage variation with time, which serve as inputs to the battery life model. Various charging and battery thermal management scenarios will be presented in future work.

Subsequent analysis compares metrics of the Texas cycles to UDDS, HWY, and US06 standard drive-cycles. To achieve an appropriate mix of CD and CS operation, either four or five repetitions of the UDDS, HWY and US06 standard drive cycles are simulated so that each cycle's daily travel distance falls as close as possible to the Texas average of 38.9 miles/ day. These UDDS, HWY, and US06 cycles are weighted with appropriate rest days such that the annual mileage of each is 12,375 miles/yr. The United States Advanced Battery Consortium (USABC) cycle-life test protocol is also simulated [23]. The PHEV10 USABC cycle simulated here uses both the $\mathrm{CD}$ and $\mathrm{CS}$ portions of the test protocol. The PHEV40 USABC cycle uses only the CD portion of the test. This is to keep the implied daily travel distance as close as possible to the Texas drive-cycle average.

\section{DRIVE-CYCLE COMPARISON}

Figure 7 shows histograms of daily travel distance, travel time, average speed, and maximum acceleration. These factors strongly influence battery charge/discharge rate, heat generation rate, and daily energy throughput. Daily travel distance results (Figure 7a) show $66 \%$ of the Texas driving trips are less than 40 miles per day and $14 \%$ of drive cycles are less than 10 miles per day. From a fuel economy perspective, the PHEV40 will accommodate a greater percentage of these drive cycles in the electric CD-mode of operation compared to the PHEV10. The implication for battery life is that PHEV40s will be less likely to discharge through their entire CD energy compared to PHEV10s. Fewer PHEV40s may encounter cycle life limitations compared to PHEV10s.

Figure 8 gives statistics of charge/discharge-throughput calculated with Eq. (11). The metric aggregates all single-day cycling encountered by the battery into a single number. It includes large perturbations in DOD due to CD cycles and small perturbations due to acceleration/deceleration events and CS cycles. The PHEV10 and PHEV40 both have a group of drive cycles clustered near 0.55 to $0.65100 \%$ DODequivalent cycles/day. These groups correspond to the useable SOC cycling windows chosen in sizing the battery (Table 3) and represent the population of drive cycles that fully deplete their battery's useable $\mathrm{CD}$ energy. For the PHEV10, there are few drive-cycles with travel distance less than 10 miles/day, and the left side of the histogram in Figure $\underline{8 \mathrm{a}}$ is rather sparse. For the PHEV40, there are many drivecycles with travel distances less than 40 miles/day, and the left side of the histogram in Figure $8 \mathrm{~b}$ has a broad distribution of partial cycles/day. Results in Figure 8 consider just a single recharge of the battery per day. Charge/dischargethroughput of the small PHEV10 battery, which will be shown in future work, can increase significantly when multiple recharges/day are considered. This would shift much of the histogram in Figure 8a to the right, representing a more severe cycle-life requirement. 

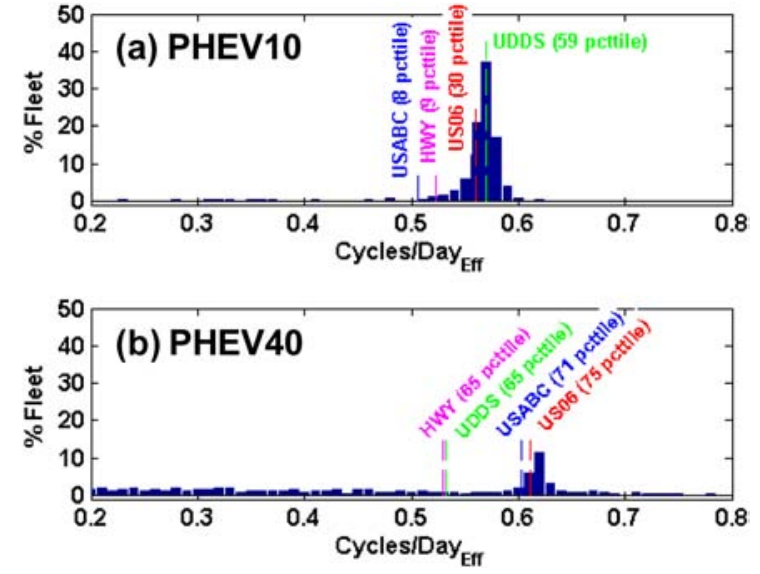

Figure 8. Model-predicted 100\% DOD-equivalent cycles per day.

Figure 9 shows the distributions of PHEV10 and PHEV40 $I^{2} R$ battery heat generation rates for the 782 drive cycles. The US06 cycle, with aggressive accelerations and high average speed, produces heat at a $99^{\text {th }}$ to $100^{\text {th }}$ percentile rate. The USABC cycle, a stair-stepped charge/discharge profile lacking second-by-second charge/discharge perturbations, does not generate much heat relative to the other cycles according to the $I^{2} R$ battery heat generation model.
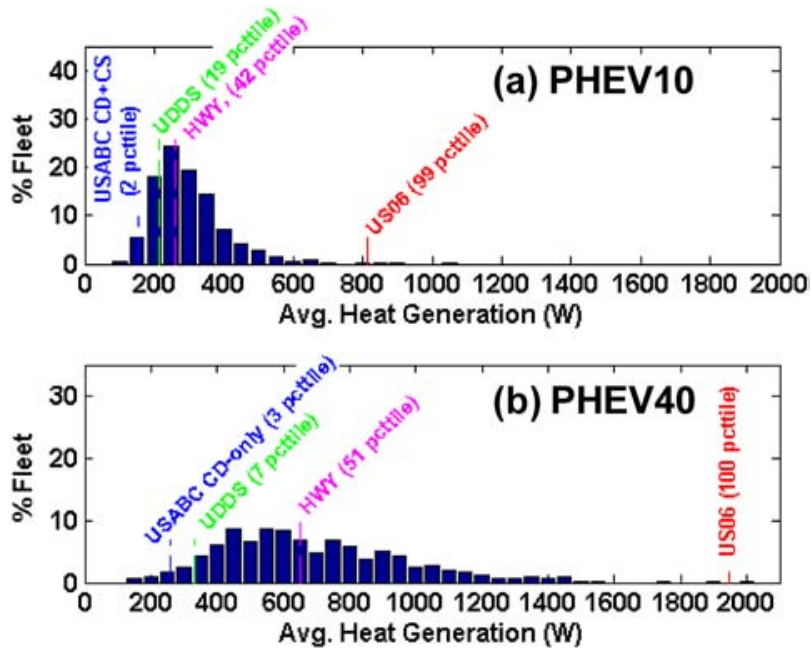

Figure 9. Model-predicted average heat generation rate during driving.

Figure 10 shows life simulation results for the 782 Texas drive-cycles for the PHEV10 and PHEV40. Distributions show the prediction of remaining capacity after 8 years of vehicle operation under each individual drive-cycle. The average-, worst-, and best-case outcomes are similar for the PHEV10 and the PHEV40. This is influenced by the battery sizing assumptions in Table 3. Recall that the PHEV10 uses $50 \%$ of available energy at the beginning of battery life and
$80 \% \mathrm{SOC}_{\text {max }}$. The PHEV40 uses $60 \%$ of available energy at the beginning of battery life and $90 \% \mathrm{SOC}_{\max }$.

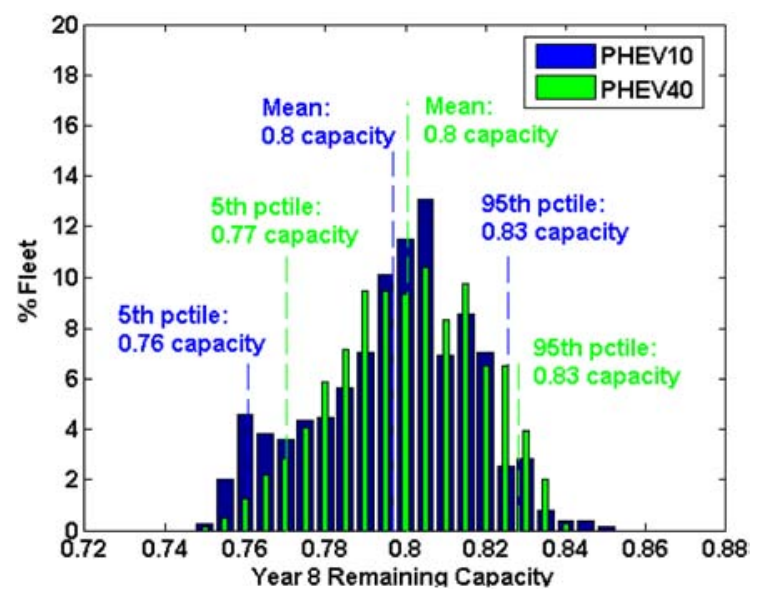

Figure 10. Battery remaining capacity at Year 8 for 782 drive-cycles. Battery temperature is fixed at $28^{\circ} \mathrm{C}$ in this simplified thermal scenario.

Small differences are evident between the two PHEVs' distributions. The PHEV10 has a larger percentage of vehicles encountering worst-case cycle-life compared to the PHEV40. (In Figure 10, blue bars are taller than green bars in the 0.75 to 0.77 remaining capacity range.) This difference is caused by the high percentage of PHEV10s that utilize their entire CD energy each day, as previously discussed for Figure $\underline{7 \mathrm{a}}$ and Figure 8. At the opposite end of the histogram are best-case battery life cases. These correspond to vehicles with small daily driving distances. For these vehicles, battery life is predominantly dictated by storage conditions. A small group of PHEV10 batteries have an apparent longer life than their PHEV40 counterparts because they are stored near $80 \%$ $\mathrm{SOC}_{\max }$ (PHEV10) rather than $90 \% \mathrm{SOC}_{\max }$ (PHEV40).

\section{CONCLUSIONS}

Battery life is dictated by complex interactions of temperature history, SOC history, and charge/discharge cycling conditions across multiple time scales. This paper presents an initial attempt to analyze the impact of each separate effect on PHEV battery life. The approach is based on a semi-empirical battery life model for the graphite/NCA chemistry that allows interpolation of battery degradation rates across different temperature, open-circuit voltage, and DOD operating profiles. Other chemistries or designs may have different aging behavior.

Analysis of storage-related degradation for 100 U.S. geographic environments suggests several strategies to reduce fade related to calendar age. Storage degradation in worstcase hot climates and temperatures can be mitigated by reducing the time spent at high SOC. One approach is to overdesign the system with a maximum SOC limit less than 
$100 \%$, for example, by using the battery only up to $80 \%$ or $90 \% \mathrm{SOC}_{\max }$. Of course, sizing the battery in this conservative manner makes it more expensive. For batteries designed with a conservative $\mathrm{SOC}_{\max }$, an adaptive control strategy might gradually increase $\mathrm{SOC}_{\max }$ and allow increased electric-range performance for vehicle not experiencing worst-case thermal conditions. Seasonal adjustments may increase $\mathrm{SOC}_{\max }$ during cold winter months to help compensate for sluggish battery performance and vehicle electric range at cold temperatures. Other strategies to reduce time spent at high SOC include just-in-time (delayed) charging and/or intentional partial-depletion of battery energy from a vehicle parked in a hot environment (e.g., by running the cooling system) until an acceptable SOC for long-term storage is reached. Calendar life may also be greatly increased by using a refrigeration system and insulation to isolate the battery from peak hot temperatures. Such a system may operate on a regular periodic basis for a parked vehicle connected to the electrical grid.

Analysis of cycling-related degradation compared attributes of UDDS, HWY, US06 and USABC cycles to 782 single-day drive-cycles recorded in a light-duty vehicle travel survey in Texas. Important attributes of driving cycles are cyclic throughput-dictating the daily average number of charge/ discharge cycles, and heat generation rate-dictating requirements for battery thermal management system design. Worst-case PHEV driving and charging patterns are those with high utilization of charge-depletion mode of operation. However, electricity is less expensive than petroleum operation and can financially offset shorter battery life. Future work will investigate driving and charging patterns in further detail to identify designs and controls that extend the life and reduce the cost of EDV battery systems.

\section{REFERENCES}

1. United States Council for Automotive Research, USABC Plug-in HEV Battery Goals, http://uscar.org/guest/ article view.php?articles $\mathrm{id}=85$.

2. Wood, E., Alexander, M., Bradley, T.H., "Investigation of battery end-of-life conditions for plug-in hybrid electric vehicles," J. Power Sources 196 (2011) 5147-5154.

3. Ploehn, H.J., Ramadass, P., White, R.E., "Solvent diffusion model for aging of lithium-ion battery cells," J. Electrochemical Society, 151 (3), 2004, A456-A462.

4. Safari, M., Morcrette, M., Teyssot, A., Delacourt, C., “A Multimodal physics-based aging model for life prediction of Li-ion batteries" J. Electrochem. Soc., 156(3), A145-A153 (2009)

5. Spotnitz, R., "Simulation of capacity fade in lithium-ion batteries," J. Power Sources, 113(1), 2003, 72-80.

6. Smith, K., Markel, T., Pesaran, A., "PHEV battery tradeoff study and standby thermal control," 26th Int. Battery Seminar \& Exhibit, Fort Lauderdale, FL, March 16-19, 2009.
7. Idaho National Laboratory, Technology Life Verification Testing, Idaho Falls, ID, 2010, INEEL-EXT-04-01986.

8. Wang, J., Liu, P., Hicks-Garner, J., Sherman, E., Soukiazian, S., Verbrugge, M., Tataria, H., Musser, J., Finamore, P., "Cycle-life model for graphite-LiFePO4 cells," J. Power Sources 196(2011) 3942-3948.

9. Peterson, S., Apt, J., Whitacre, J. (2010) "Lithium-ion battery cell degradation resulting from realistic vehicle and vehicle-to-grid utilization," J. of Power Sources, v195 p2385-2392.

10. National Renewable Energy Laboratory, "Design of Electric Drive Vehicle Batteries for Long Life and Low Cost," Golden, CO, 2010, NREL/PR-540-48933.

11. Santhanagopalan, S., Zhang, Q., Kumaresan, K., White, R.E., "Parameter estimation and life modeling of lithium-ion cells,” J. Electrochem. Soc. 155(4) 2008, A345-A353.

12. Verbrugge, M.W., Cheng, Y.-T., "Stress and strainenergy distributions within diffusion-controlled insertionelectrode particles subjected to periodic potential excitations," J. Electrochem. Society, 156(11) 2009, A927A937.

13. Broussely, M., "Aging of Li-ion batteries and life prediction, an update," 3rd Int. Symposium on Large Li-ion Battery Technology and Application, Long Beach, California, May 2007.

14. Hall, J., Lin, T., Brown, G., Biensan, P., and Bonhomme, F., "Decay processes and life predictions for lithium ion satellite cells," 4th Int. Energy Conversion Engineering Conf., San Diego, California, June 2006.

15. Smart, M., Chin, K., Whitcanack, L., and Ratnakumar, B., "Storage characteristics of Li-ion batteries," NASA Battery Workshop, Huntsville, Alabama, Nov. 2006.

16. Broussely, M., Chap. 13 in: Advances in Li-ion Batteries, van Schalkwijk, W., and Scrosati, B., editors. New York: Kluwer Academic / Plenum Publishers, 2002.

17. R.L. Polk \& Co., https://polk.com.

18. National Renewable Energy Laboratory, National Solar Radiation Database, Typical Meteorological Year Database 3, Golden, CO.

19. National Renewable Energy Laboratory Strategic Initiative Working Group Report: Thermal Model of Gen 2 Toyota Prius, Kandler Smith, Ahnvu Le, Larry Chaney.

20. Ojah, M., Pearson, D., "2006 Austin/San Antonio GPSEnhanced Household Travel Survey," Texas Transportation Institute, August 2008.

21. Earleywine, M., Gonder, J., Markel, T., Thornton, M., "Simulated Fuel Economy and Performance of Advanced Hybrid Electric and Plug-in Hybrid Electric Vehicles Using In-Use Travel Profiles," Vehicle Power and Propulsion Conference, Lille, France, Sept. 2010. 
22. U.S. Department of Transportation, Federal Highway Administration, 2005 National Household Travel Survey. URL: http://nhts.ornl.gov.

23. Idaho National Laboratory, Battery Test Manual For Plug-In Hybrid Electric Vehicles, Idaho Falls, ID, 2010, INL/ EXT-07-12536.

\section{CONTACT INFORMATION}

The authors may be reached via email at

kandler.smith@nrel.gov

matthew.earleywine@nrel.gov

eric.wood@nrel.gov

jeremy.neubauer@nrel.gov

ahmad.pesaran@nrel.gov

\section{ACKNOWLEDGMENTS}

The authors gratefully acknowledge funding and guidance from the U.S. Department of Energy Office of Vehicle Technologies, Energy Storage program managers David Howell and Brian Cunningham and for data and helpful discussions from Loïc Gaillac, John C. Hall, Tony Markel, Naum Pinsky, and Marshall Smart.

The Engineering Meetings Board has approved this paper for publication. It has successfully completed SAE's peer review process under the supervision of the session organizer. This process requires a minimum of three (3) reviews by industry experts. ISSN 0148-7191
Positions and opinions advanced in this paper are those of the author(s) and not necessarily those of SAE. The author is solely responsible for the content of the paper.

SAE Customer Service:

Tel: 877-606-7323 (inside USA and Canada)

Tel: 724-776-4970 (outside USA)

Fax: 724-776-0790

Email: CustomerService@sae.org

SAE Web Address: http://www.sae.org

Printed in USA 